\title{
Effects of thermal contrast on size estimation of debonds in different external wall's composite finishes via passive infrared thermography and a modified gradient algorithm
}

\author{
by Janet F. C. Sham*, Wallace W. L. Lai* and S. Y. Chiu*
}

*The Hong Kong Polytechnic University, The Department of Land Surveying and Geo-Informatics, janet.sham@polyu.edu.hk and wallace.wai.lok.lai@polyu.edu.hk

\begin{abstract}
This paper aims to present a study on the effects of thermal contrast in various external wall's composite finishes on estimated debond size by using passive infrared thermography and a modified gradient algorithm. The effects of thermal contrast on debond size estimation by the proposed method were evaluated under 2 conditions: different finishes materials and changes of heat absorption during a 13-hr diurnal cycle. This study reports a quantitative investigation of detectability by comparing its estimated size with actual size.
\end{abstract}

\section{Introduction}

Nowadays, passive infrared thermography is one of the widely used techniques for debond detection in external wall in Hong Kong. Usually, the results are presented qualitatively by indicating the suspected debond areas on building elevation plan. It depends on the visibility of the debonds in thermal images. The severity of the detected debonds are judged by the experience of the interpreter and the size of the debond shown on the thermogram can be adjusted freely by controlling the temperature span. Washer et al. [1] also argued that the anomalies can be shown as less severe or even appeared as if there is no anomaly by changing the temperature span. Some studies suggested to define detectability of debonds by referring to thermal contrast $(\Delta \mathrm{T})$, i.e. temperature difference between intact area and debond area. Clark et al. [2] suggested that the effective detectible range of debond is approximately $0.2-0.3^{\circ} \mathrm{C}$ while Hiasa et al. [3] suggested that the "almost certain range for detectability" using IRT for delamination detection on bridge structures is above $0.4^{\circ} \mathrm{C}$. However, unlike bridge structures, buildings' external walls are not just finished with rendering or even fair-faced concrete, they are covered with different finishing materials such as different colors of paintings, ceramic tiles and mosaic tiles etc for aesthetic purpose. This study demonstrates the effects of thermal contrast observed on different building finishing materials during a 13-hr diurnal cycle on debond size estimation. The detectability of debonds using IRT is not simply by referring to the visibility of the debond in thermal image, but to quantify the detectability of debond by calculating the percentage error of size estimation through a gradient algorithm. The new gradient algorithm used in this study was modified based on the study of Lai's et. al. [4] that governs the selection of gaussian moments by using $2^{\text {nd }}$ order derivative instead of manual adjustment for size estimation.

\section{Passive thermography for defect detection}

There are mainly two categories of thermography techniques for defect detection, i.e. active and passive thermography. Passive thermography is applied under natural sunlight and no active heat source (i.e. heat generator) is required whereas active thermography requires external heat source (either short or long pulse). The principle of infrared thermography for defect detection is that subsurface defect which is filled with air acts as a thermal insulator and preventing heat from penetrating to the region underneath the delamination. This phenomenon is due to the difference in thermal conductivities between air $\left(0.0241 \mathrm{~W} / \mathrm{m}^{\circ} \mathrm{C}\right)$ and the material of the target object, e.g. concrete $\left(1.6 \mathrm{~W} / \mathrm{m}^{\circ} \mathrm{C}\right)$. 3-dimensional heat transfer by conduction can be described with the following equation

$$
C \rho \frac{\partial T}{\partial t}=\frac{\partial}{\partial x}\left(k_{x} \frac{\partial T}{\partial x}\right)+\frac{\partial}{\partial y}\left(k_{y} \frac{\partial T}{\partial y}\right)+\frac{\partial}{\partial z}\left(k_{z} \frac{\partial T}{\partial z}\right)
$$

Equation 1

Where $\mathrm{C}$ represents specific heat capacity $\left(\mathrm{J} \mathrm{kg}^{-1} \mathrm{~K}^{-1}\right)$, $\rho$ represents density $\left(\mathrm{kg} \mathrm{m}^{-3}\right)$, $\mathrm{T}$ represents temperature in degree kelvin $(\mathrm{K})$, $\mathrm{t}$ represents time lapse, $\mathrm{k}_{\mathrm{x}}, \mathrm{k}_{\mathrm{y}}, \mathrm{k}_{\mathrm{z}}$ represent the anisotropic thermal conductivities in three major directions of heat transfer in the material, assuming that there is no heat generation within the media. In such case, the heat exerted on the surface above the defect will be trapped and accumulated and hence increase the surface temperature. The area above the defect will becomes warmer than the surrounding during daytime. On the hand, the area above the delamination cools down faster than the surrounding at night time [5]. 
Under passive thermography, sometimes subsurface defects cannot be observed since the heat source (i.e. sunlight) is not controllable. Heat source cannot be adjusted to increase the power for defect observation. Therefore, the detectability of subsurface defects is highly affected by the surrounding environment such as the orientation of the building to the sunlight, cloud coverage, wind speed and most importantly the time of data collection. Despite of the limitation and un-controllable situation, passive thermography is still a better choice over the conventional inspection techniques such as hammer tapping and chain drag under proper condition for civil structures inspection [6,7] because it is a non-contact and invasive technique. IR images can be taken over a large surface area of the building [8-10].

\section{On-site testing}

The experiment was carried out at The Road Laboratory Testing site of the Hong Kong Polytechnic University located at Shek Mun. In this experiment, a FLIR T650sc infared camera with spatial resolution of $640 \times 480$ pixels and thermal sensitivity of $20 \mathrm{mK}$ was used for the experiment.

\section{Table 1: Specifications of IR camera used in the experiment}

\begin{tabular}{|l|l|}
\hline Detector type & Uncooled microbolometer \\
\hline Thermal sensitivity (NETD) & $<0.02^{\circ} \mathrm{C}$ \\
\hline Accuracy & $\pm 1^{\circ} \mathrm{C}$ or $\pm 1 \%$ of reading for limited temperature range \\
\hline Resolution & $640 \times 480$ \\
\hline Spectral range & $7.5-13.0 \mu \mathrm{m}$ \\
\hline Frame rate & Max. $30 \mathrm{~Hz}$ \\
\hline Field of View & $25^{\circ} \times 19^{\circ}$ \\
\hline
\end{tabular}
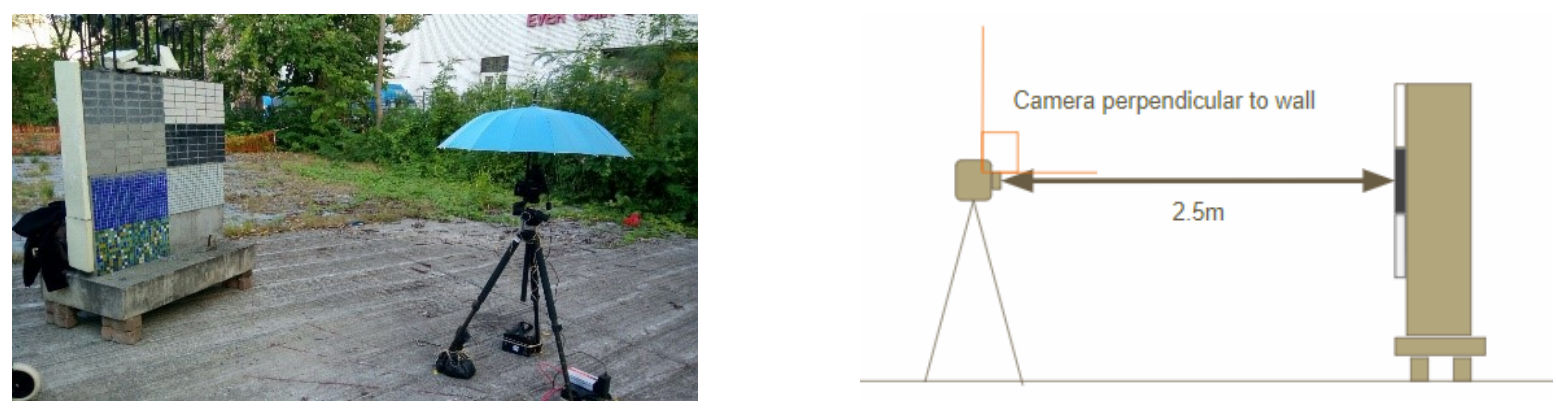

Fig 1: Experiment setup on site

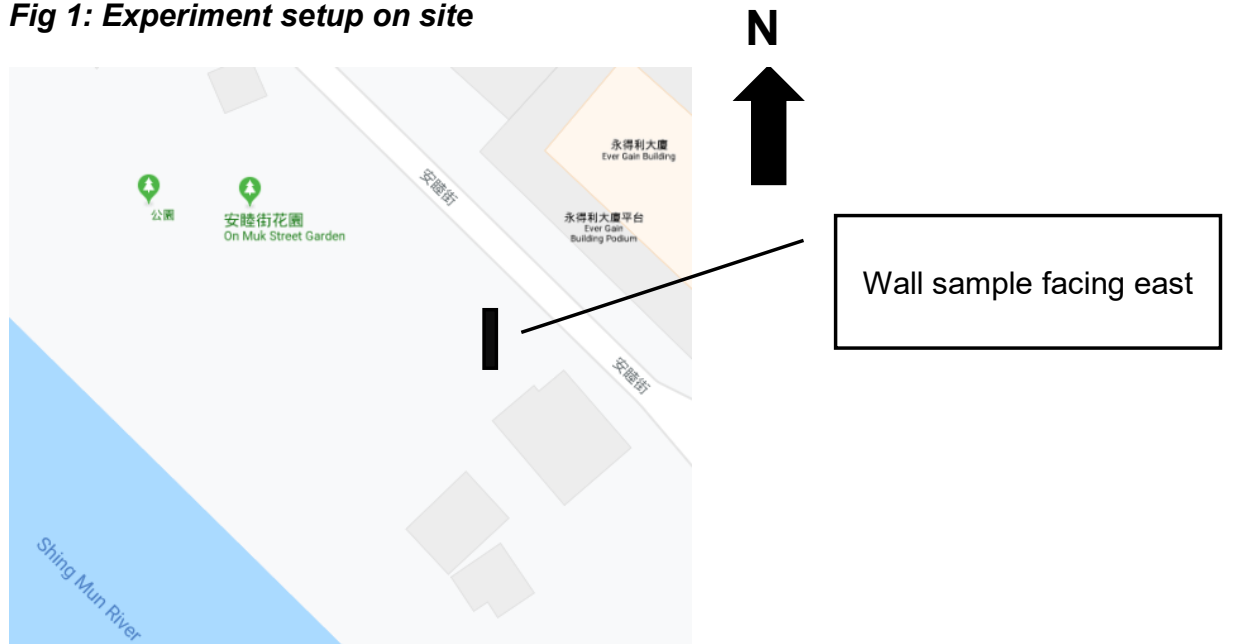

Fig 2: Location and orientation (to the East) of the sample wall.

The reinforced concrete wall was placed at a site with spacious environment and hence enables more even sunlight absorption to the wall. The temperature change of the wall was monitored with an infrared camera FLIR T650sc in every $5 \mathrm{mins}$ and at $2.5 \mathrm{~m}$ from the wall as shown in Fig 3 . The experiment was carried out on $6^{\text {th }}$ February 2018 and thermal data were collected continuously from $8 \mathrm{am}$ to $9 \mathrm{pm}$. The sample wall was facing to the east in order to maximize the heat energy received from the sunlight. 
Table 2: Summary of weather condition on the date of data collection

\begin{tabular}{|l|l|}
\hline Date & $6^{\text {th }}$ February, 2018 \\
\hline Time & $08: 00-21: 00$ \\
\hline Venue & Shek Mun, Shatin \\
\hline Average Temperature & $7.9^{\circ} \mathrm{C}-14.2^{\circ} \mathrm{C}$ \\
\hline Humidity & $40 \%-66 \%$ \\
\hline Average Ambient Gamma Radiation & $0.12 \mathrm{MS}$ (Tai Mei Tuk) \\
\hline Cloud Coverage & $68 \%$ \\
\hline Wind Speed & $25 \mathrm{~km} / \mathrm{h}$ \\
\hline
\end{tabular}

\subsection{Sample design}

A reinforced concrete wall with dimension $1.16 \mathrm{~m} \times 1.9 \mathrm{~m} \times 2 \mathrm{~m}$ was built to simulate an external wall under natural sunlight throughout the semi-diurnal cycle, i.e. from $8 \mathrm{am}$ to $9 \mathrm{pm}$ in every 5 minutes, and hence 1256 thermal images were collected for the study. The surface of the sample wall was divided into 8 parts. 7 out of the 8 parts were covered with 7 types of finishing materials and one part left as fair-face concrete as shown in Fig 3.

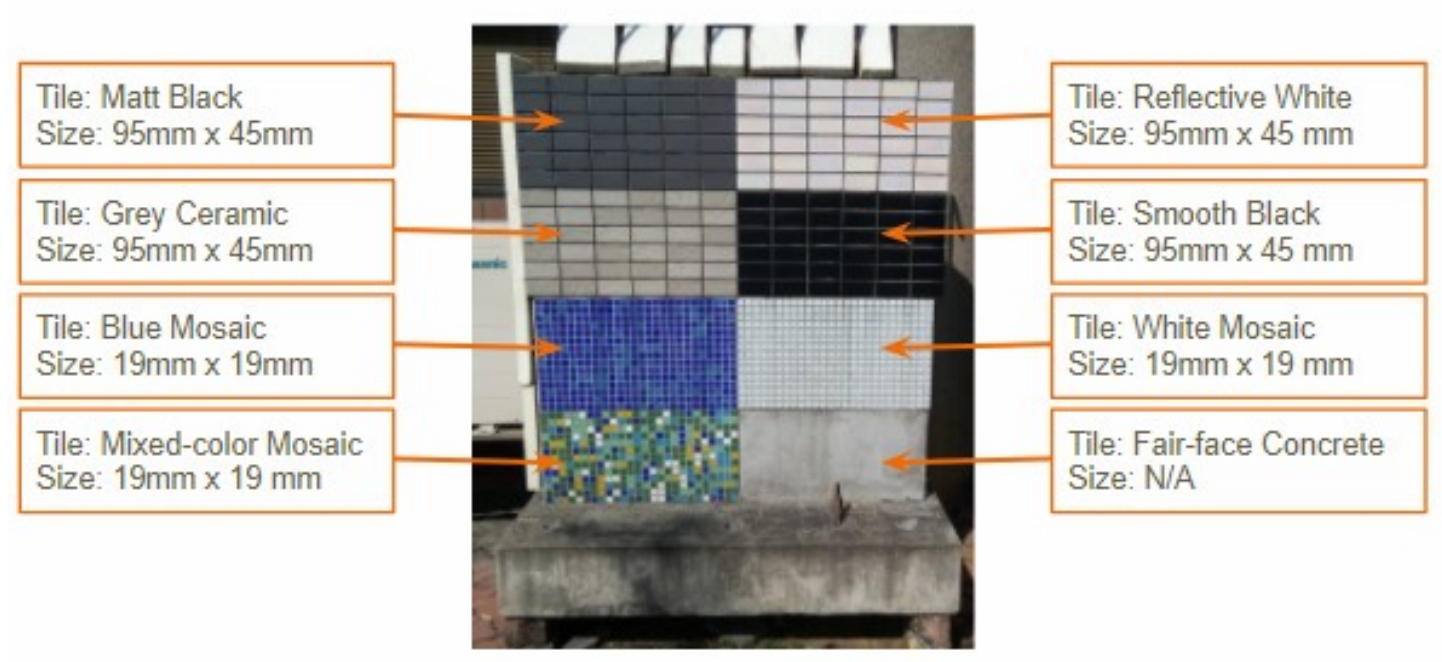

Fig 3: Sample wall covered with 7 different finishes materials and one part of fair-face concrete.

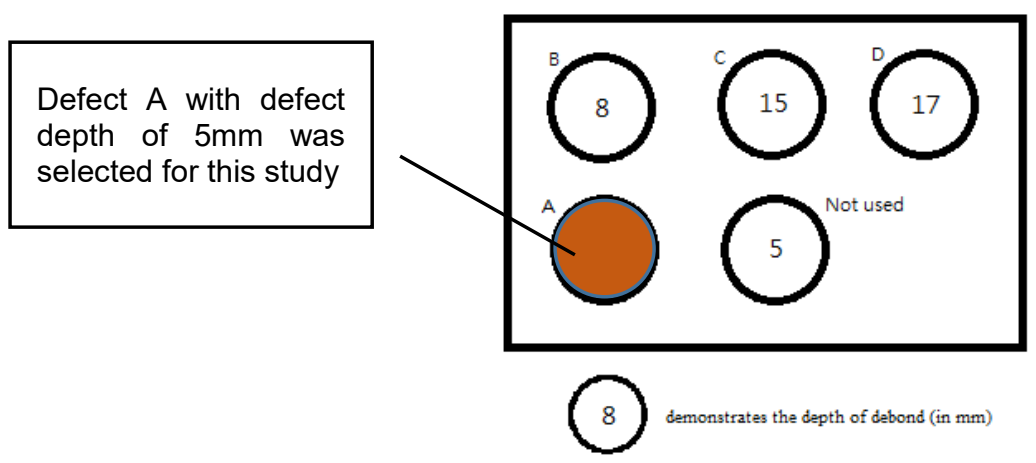

Fig 4: Circular debonds located at different depths (ranging from $5 \mathrm{~mm}-17 \mathrm{~mm}$ ), only defects with $5 \mathrm{~mm}$ depth (Debond A highlighted in Red) was selected for this study.

All the 8 parts of the concrete wall were embedded with five low-density and $7.5 \mathrm{~cm}$ diameter polystyrene foam plates (A-D) with defect depth of ranging from 5-17 mm from the wall surface. This study only selected defect depth of $5 \mathrm{~mm}$ for investigation. According to Holst's research, subsurface defects will changes from hot spots during heat absorption to cold spot during heat dissipation [5]. The temperature span was to $18.5^{\circ} \mathrm{C}-27.5^{\circ} \mathrm{C}$ of the thermogram, this phenomenon can be seen in this experiment as shown in Fig 5. 
Hot Spot

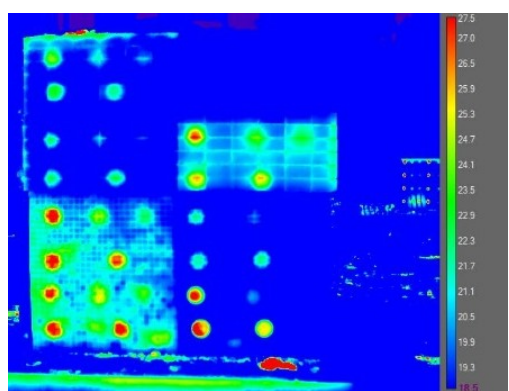

(a)
Transition period

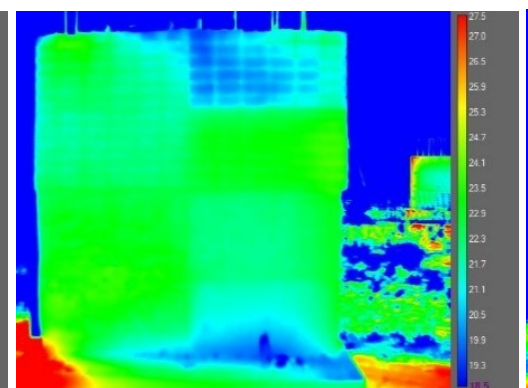

(b)

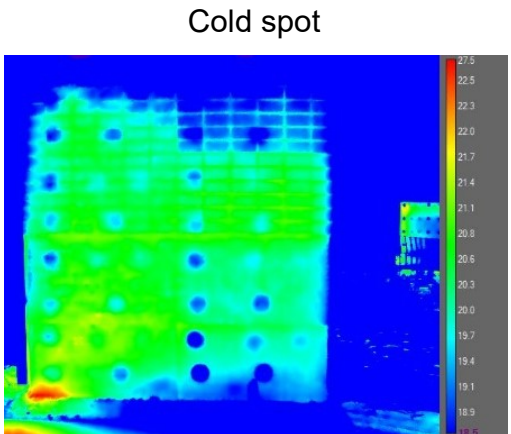

(c)

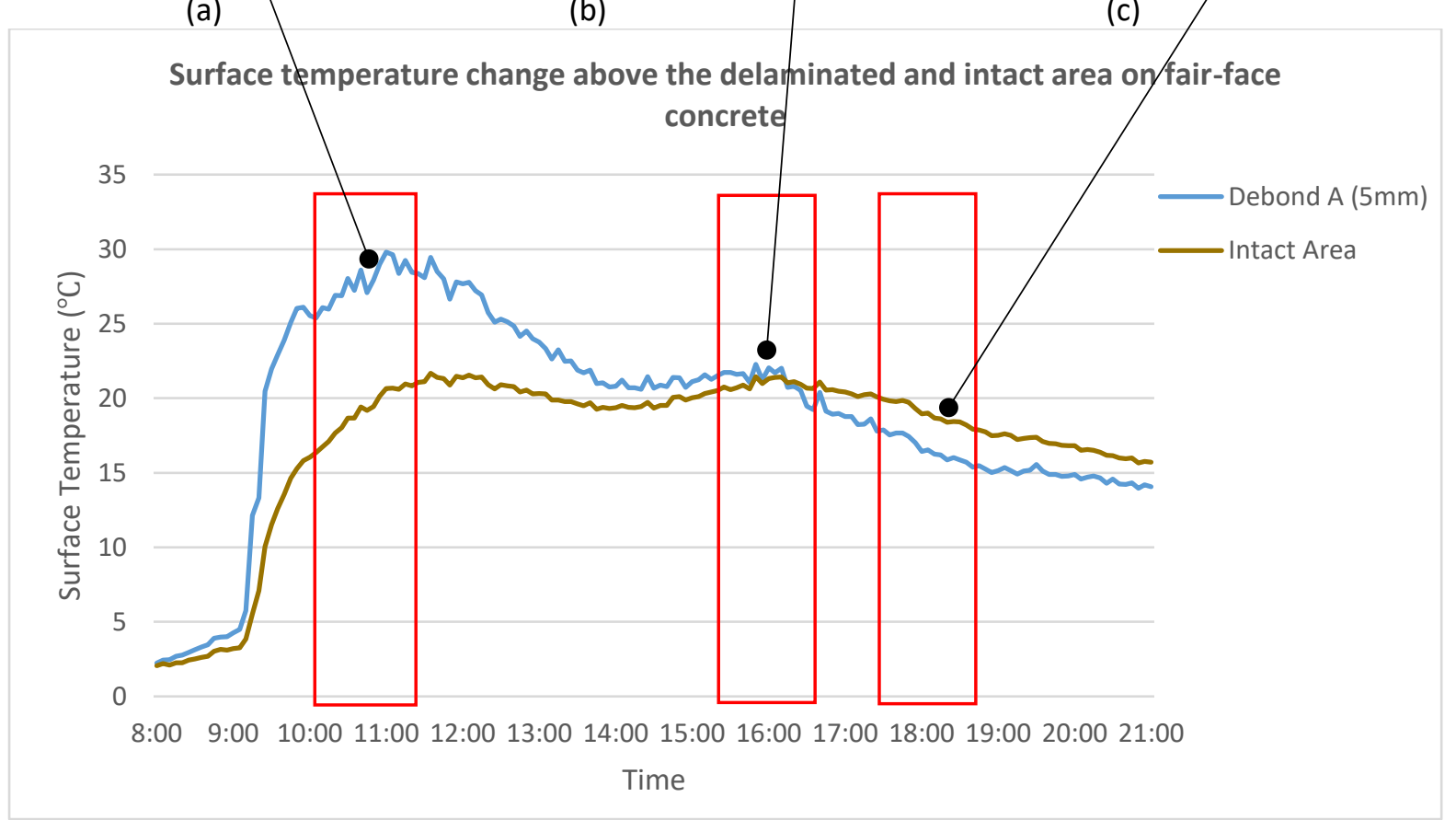

(d)

Fig 5: Thermograms of defects on the sample wall shown as (a) hot spot, (b) disappeared (transition period), (c) cold spot at 10:44am, 4:54pm and 6.24pm respectively; (d) Surface temperature change above the delaminated and intact areas on fair-face concrete surface.

According to Fig 5, the whole data collection period can be divided into three parts: (1) heat absorption period in which hot spots can be observed on the thermogram as shown in Fig 5(a), (2) transition period, it is also called blind moment because defects will be disappeared during this period of transition from heat absorption to heat dissipation period, thermal contrast between defected area and intact area will becomes zero as shown in Fig 5(b) and (3) heat dissipation period in which defects will be shown as cold spots as shown in Fig 5(c). It is because the higher energy accumulated on the defect surface will cools down faster than the surrounding intact area.

The image analysis process was carried out by using an in-house Labview program which was modified from the original program developed by Lai's team [4] for this study. The raw data of the thermogram in.csv form was imported into the program for processing. Originally, the program was only capable to process one thermogram at one time. In the modified program, sequence of thermal images could be processed at the same time. It works faster to process the change of defect size throughout the whole recording period. The sizes of the debond were estimated by the following modified procedures was based on Lai's approach [4]:

1. Outline the region of interest (ROI) where shows abnormal temperature distribution considered as debonds by the operators. The ROI should cover the whole debond and do not overlap with the edge of the debond. 

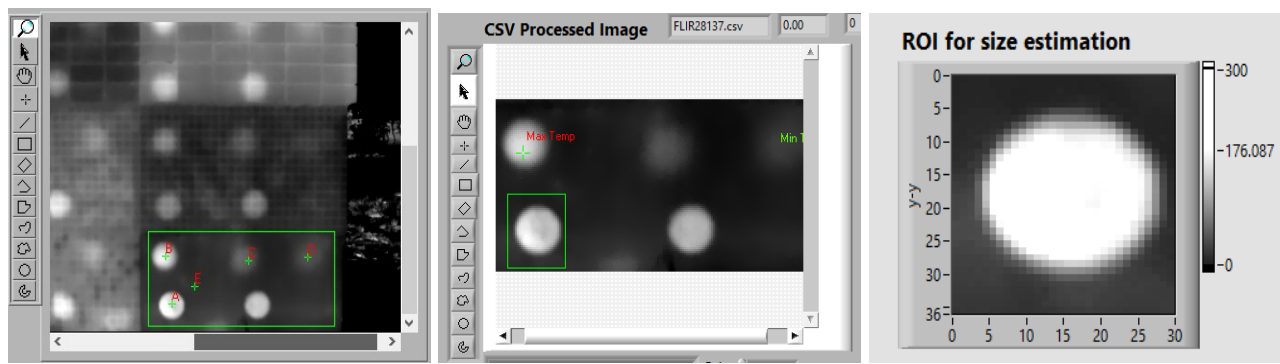

Fig 6: Outline Region of Interest from the whole thermogram.

3. The 2-D thermogram within the ROI is broken down into 1-D gaussian shaped temperature profile of pixel line in $x-x$ and $y-y$ directions.

4. The boundary of defect in $x-x$ and $y-y$ direction is determined by calculating the first two maximum peaks of the $2^{\text {nd }}$ derivative curve of the 1D gaussian shaped temperature profile as shown in Fig 7 .
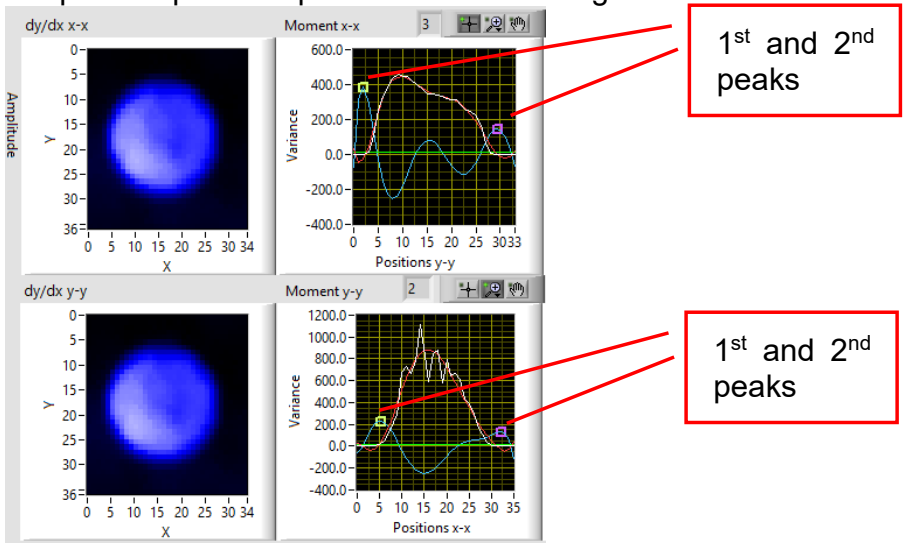

Fig 7: Determination of the defect boundary by calculation of the first two peaks of the 1st derivative curve of the 1D gaussian shaped temperature profile.

5. The areas within the selected boundary of $x-x, y-y$ directions are turned to binary data ( 0 or 1$)$ then fused to form the whole image and filtered with a median filter.
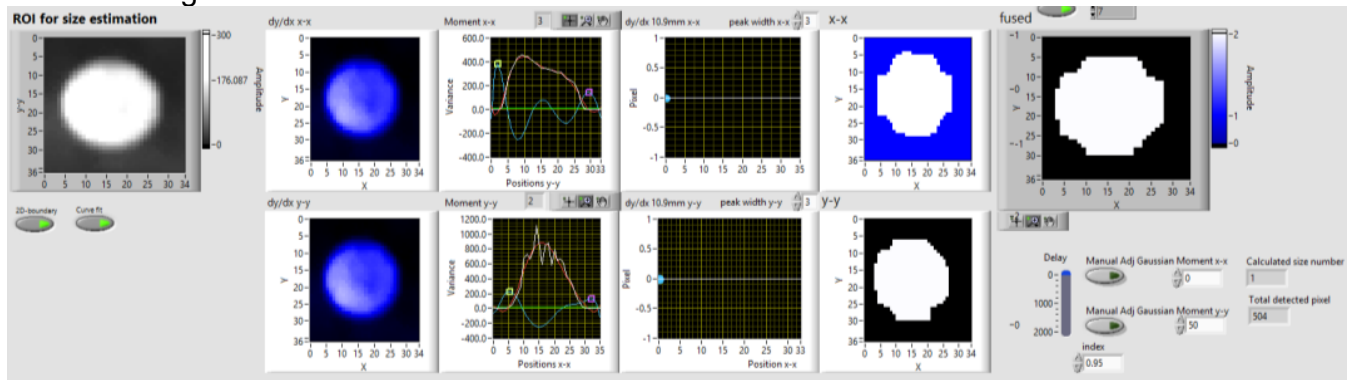

Fig 8: The region of interest in $x-x, y-y$ direction fused and form binary data

The defect which was tailor made in this study was in circular shape, therefore, the temperature profile was in gaussian shape and it will be changed with the shape of the defect. The major modification of the above gradient algorithm was that the setting of gaussian moment was set by picking the first two maximum peaks of the $2^{\text {nd }}$ derivative curve of the gaussian temperature profile instead of manual adjustment. It enabled automatic processing of the size estimation. The estimated size by the above gradient algorithm was used to be a reference of "detectability" of a defect. The principle is that the smaller the absolute percentage error of the estimated size is to the actual defect size, the more detectable it is. This study gives a quantitative value for detectability in terms of absolute percentage error.

\section{$5 \quad$ Results and Discussion}

As shown in Fig 5, the surface temperature change of the wall during a 13-hr semi-diurnal cycle from 8:00am to 9:00pm was recorded and the change of thermal contrast of the selected debond on the wall with different finishes are shown in Fig 9. The thermal contrast was changing during the day from positive thermal contrast to negative (i.e. from hot spot to cold spot). It is hard to predict the time when maximum thermal contrast happened with the fact that thermal contrast is changing during the day. This study covered three periods: heat absorption, transition period and heat dissipation period 
to determine the optimum thermal contrast for optimum detectability for different finishes materials. As mentioned before, detectability is reference to the absolute percentage error of the estimated size. With the same exposure to sunlight, some materials cannot achieve high thermal contrast as fair-face concrete as shown in Fig 9.

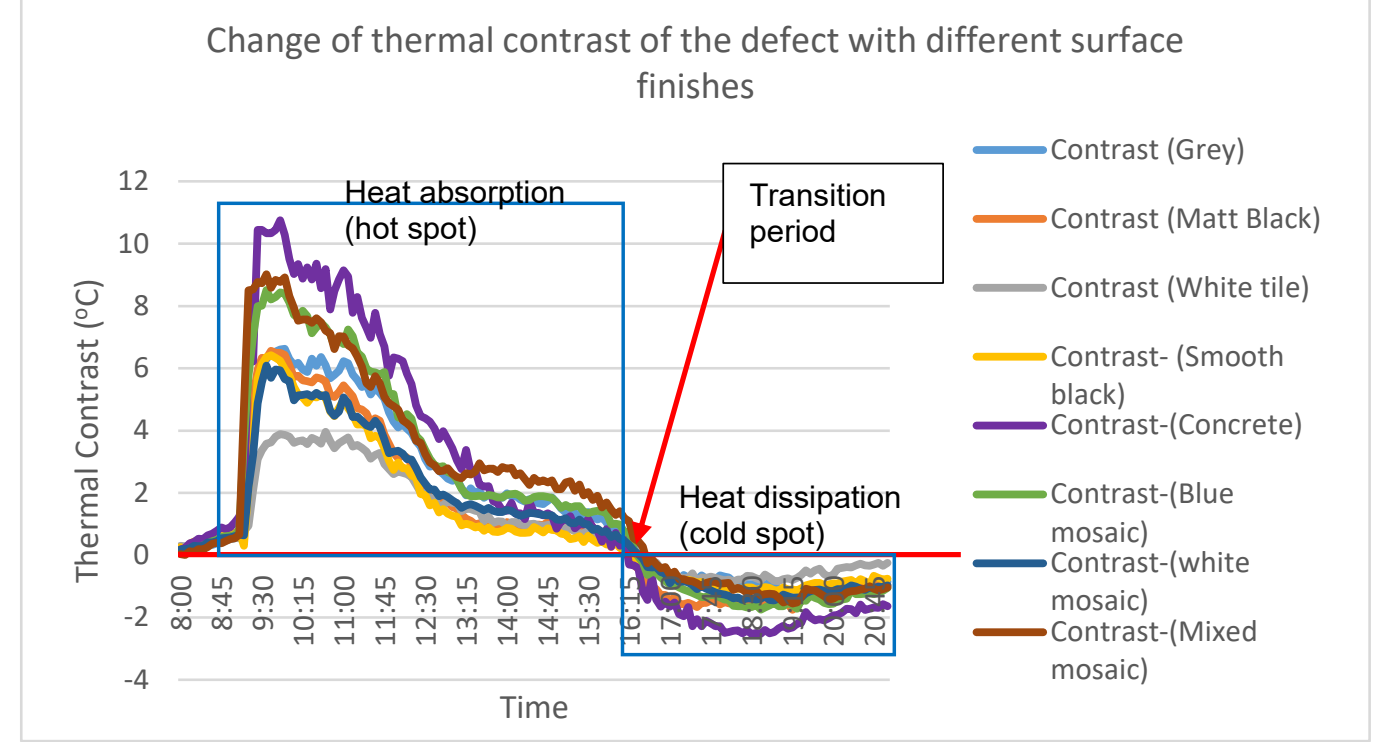

Fig 9: Change of thermal of contrast of defects with different surface finishes

Fig 9 shows that during the heat absorption period, fair-face concrete has the highest thermal contrast while white tile has the lowest thermal contrast. Different finishes materials responded differently under similar sunlight exposure. It is because of the difference in emissivity and thermal conductivities in different finishes materials [10]. Therefore, it is difficult to state one specific thermal contrast for defect detection. Quantitatively, fair-face concrete had thermal contrast larger than $10^{\circ} \mathrm{C}$ while white tile only had $4^{\circ} \mathrm{C}$ thermal contrast during heat absorption period. It also shows that fair-face concrete obtained highest contrast during heat absorption and hence releasing more during heat dissipation period. Fig 9 also shows that nearly all type of materials has transition period at around $16: 15 \mathrm{pm}$ to $5 \mathrm{pm}$ which was around sunset time. All defects are seemed to be disappeared at the transition period as shown in Fig 5(b) and the thermal contrast of all finishes materials are close to zero as shown in Fig 9. The 8 types of finishes materials are presented in two groups: (Group A) mosaic tiles plus fair-face concrete and (Group B) ceramic tiles for more easy observation. The correlation between absolute thermal contrast of 8 different finishes materials with debond depths of $5 \mathrm{~mm}$ and the absolute percentage error of estimated size are presented in Fig 10 and Fig 11.

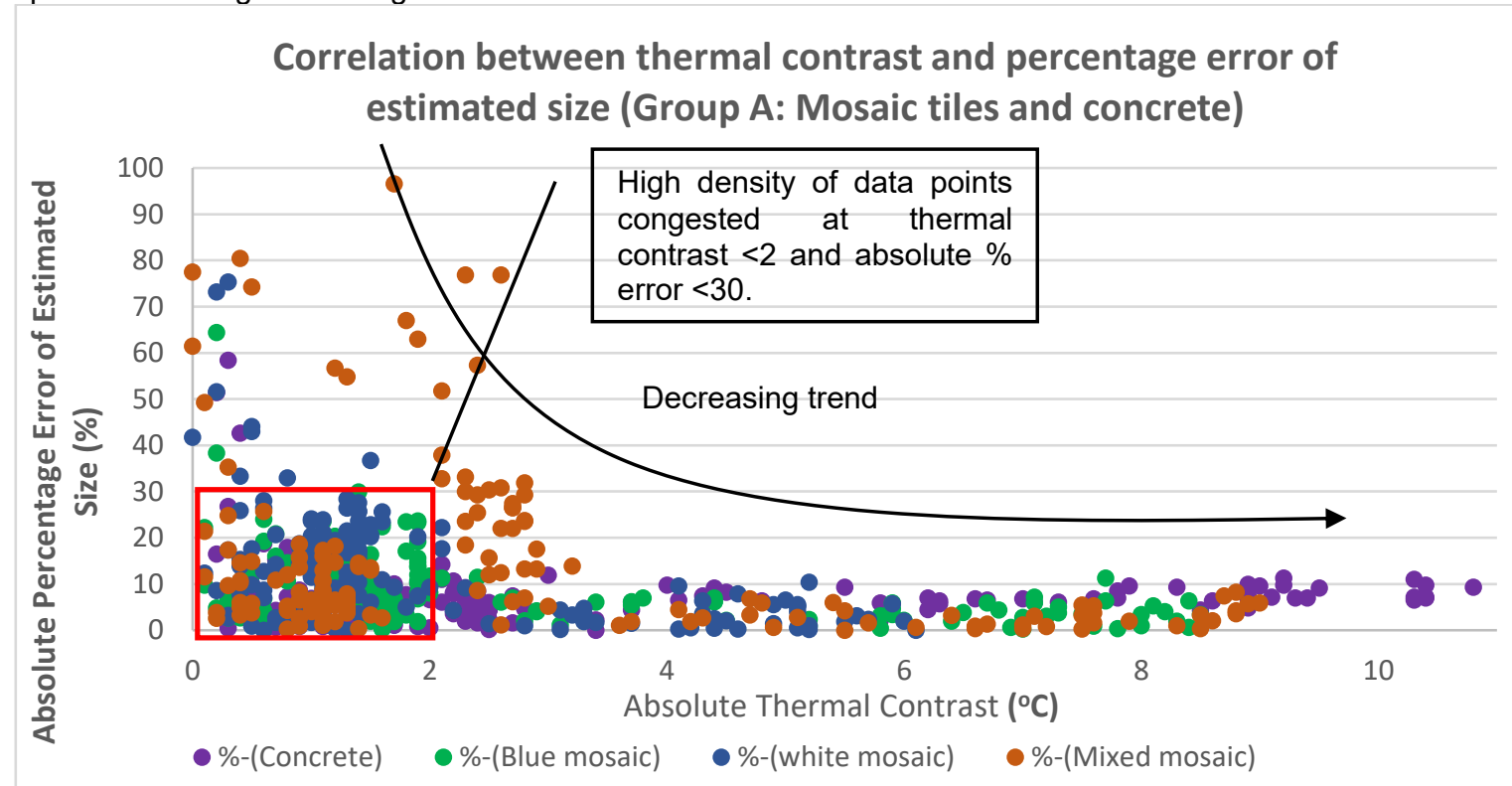

Fig 10: Correlation between thermal contrast and the percentage error of estimated size (mosaic tiles and fair-face concrete) 


\section{Correlation between thermal contrast and percentage error of estimated} size (Group B: Ceramic tiles)

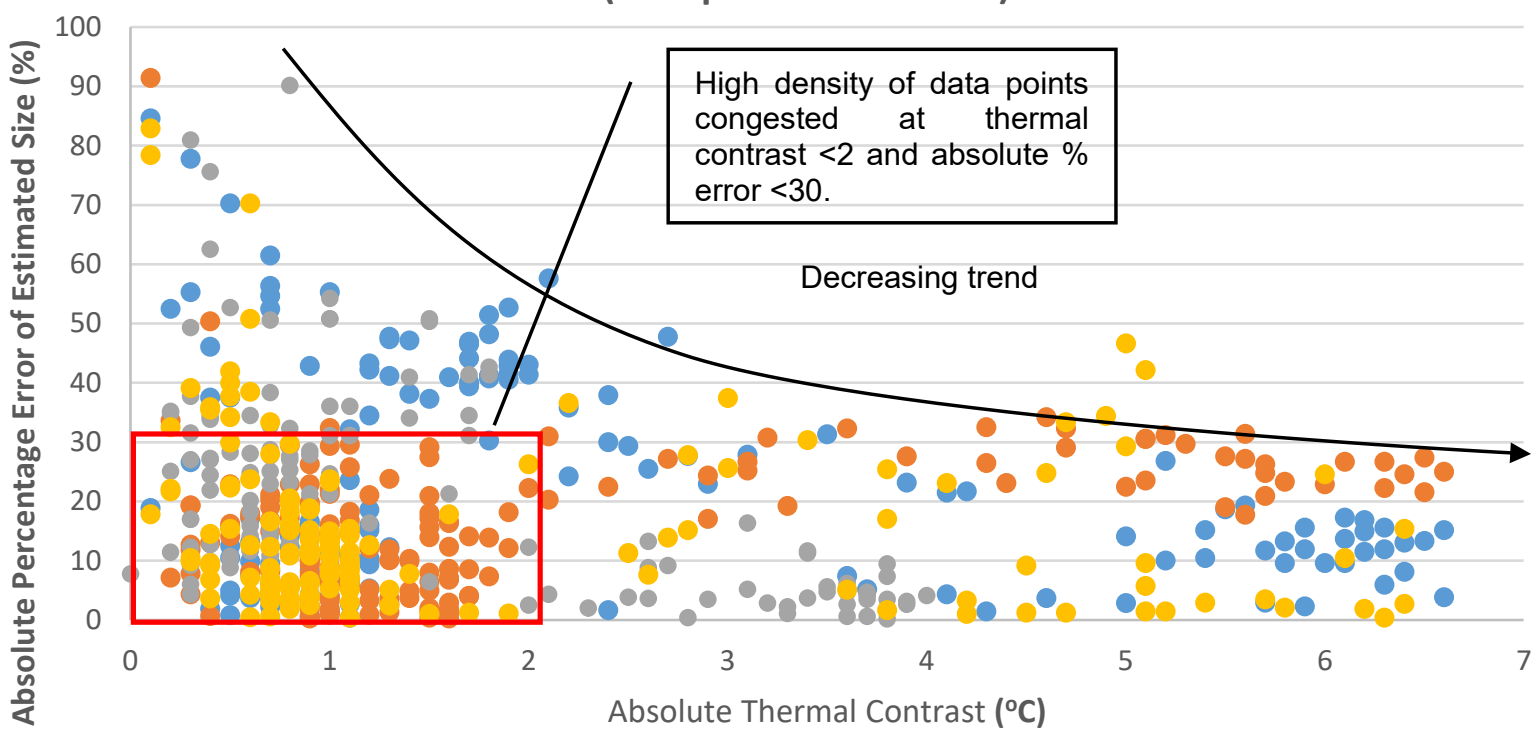

$\%$ (Grey) $\quad \%$ (Matt Black) (White tile) (Smooth black)

Fig 11: Correlation between thermal contrast and the percentage error of estimated size (Ceramic tiles)

As shown in both Fig 10 and Fig 11, there is a trend that the absolute percentage error of estimated size decreases when the absolute thermal contrast increases in all types of finishes materials. This trend is more obvious on group $A$ finishes materials as shown in Fig 10. It is observed from both Fig 10 and Fig 11 that there is a high density of data points congested to the range of thermal contrast $<2{ }^{\circ} \mathrm{C}$ and percentage error $<30 \%$. There is the reason why most of the researchers suggested that thermal contrast $>0.2^{\circ} \mathrm{C}$ to $1^{\circ} \mathrm{C}[2,3,11]$. However, data points are scattered around within this range and having relatively higher standard deviation. Different materials have different thermal responses to the absorbed sunlight energy under the same condition. In order to have clearer illustrations of the effect of absolute thermal contrast to the absolute percentage errors of the data, data points were grouped into 10 level of thermal contrast ranging from $1^{\circ} \mathrm{C}$ to $10^{\circ} \mathrm{C}$. Table 3 shows different absolute percentage error with various thermal contrast ranging from $1^{\circ} \mathrm{C}$ to $10^{\circ} \mathrm{C}$ with the corresponding standard deviation (SD) in different finishes materials.

Table 3: Summary of average absolute temperature (with standard deviation) and the corresponding thermal contrast obtained in different finishes materials.

\begin{tabular}{|c|c|c|c|c|c|c|c|c|}
\hline \multirow[t]{2}{*}{$\begin{array}{l}\text { Thermal } \\
\text { contrast }\end{array}$} & $\begin{array}{l}\text { Fair-face } \\
\text { concrete } \\
\text { (SD) in\% }\end{array}$ & $\begin{array}{l}\text { Blue mosaic } \\
\text { (SD) }\end{array}$ & $\begin{array}{l}\text { White } \\
\text { mosaic } \\
\text { (SD) }\end{array}$ & $\begin{array}{l}\text { Mixed } \\
\text { mosaic } \\
(\mathrm{SD})\end{array}$ & $\begin{array}{l}\text { Smooth } \\
\text { black } \\
\text { (SD) }\end{array}$ & $\begin{array}{l}\text { Matt Black } \\
\text { (SD) }\end{array}$ & $\begin{array}{l}\text { Reflective } \\
\text { (SD) white }\end{array}$ & $\begin{array}{l}\text { Grey } \\
\text { (SD) }\end{array}$ \\
\hline & \multicolumn{8}{|c|}{ Average $\%$ error and SD in unit of $\%$} \\
\hline $1^{\circ} \mathrm{C}$ & $8.56(10.13)$ & $11.54(8.91)$ & $\begin{array}{l}16.96 \\
(12.23)\end{array}$ & $\begin{array}{l}16.89 \\
(21.27) \\
\end{array}$ & $\begin{array}{l}15.07 \\
(14.56)\end{array}$ & $\begin{array}{l}12.94 \\
(11.72)\end{array}$ & $\begin{array}{l}26.59 \\
(17.94)\end{array}$ & $\begin{array}{l}24.76 \\
(20.61)\end{array}$ \\
\hline $2{ }^{\circ} \mathrm{C}$ & $5.8(3.53)$ & $7.57(3.45)$ & $9.32(8.09)$ & $\begin{array}{l}27.16 \\
(17.50)\end{array}$ & $19.8(10.51)$ & $23.5(4.55)$ & $5.77(4.34)$ & $\begin{array}{l}32.69 \\
(13.82) \\
\end{array}$ \\
\hline $3{ }^{\circ} \mathrm{C}$ & $4.98(4.52)$ & $5.24(2.3)$ & $2.7(1.6)$ & $5.53(5.89)$ & $\begin{array}{l}20.38 \\
(13.15)\end{array}$ & $26.96(4.61)$ & $4.9(3.67)$ & $\begin{array}{l}18.99 \\
(11.95)\end{array}$ \\
\hline $4{ }^{\circ} \mathrm{C}$ & $7.94(1.39)$ & $5.43(2.19)$ & $3.39(3.23)$ & $3.71(2.19)$ & $14.61(-)$ & $29.6(4.22)$ & $4.11(-)$ & $\begin{array}{l}10.52 \\
(10.14)\end{array}$ \\
\hline $5^{\circ} \mathrm{C}$ & $5.88(3.53)$ & $3(1.95)$ & $3.89(2.8)$ & $2.96(2.31)$ & $\begin{array}{l}14.48 \\
(17.83)\end{array}$ & $25.74(4.52)$ & - & $12.31(6.63)$ \\
\hline $6^{\circ} \mathrm{C}$ & $6.18(0.91)$ & $3.19(1.92)$ & $1.01(-)$ & $1.31(1.14)$ & $9.23(11.09)$ & $24.62(2.25)$ & - & $12.02(3.96)$ \\
\hline $7^{\circ} \mathrm{C}$ & $7.29(1.28)$ & $4.23(3.2)$ & - & $2.48(1.86)$ & - & - & - & - \\
\hline $8^{\circ} \mathrm{C}$ & $7.05(2.1)$ & $3.29(2)$ & - & $4.02(2.73)$ & - & - & - & - \\
\hline $9^{\circ} \mathrm{C}$ & $8.73(1.67)$ & - & - & $5.95(-)$ & - & - & - & - \\
\hline $10^{\circ} \mathrm{C}$ & $8.33(2.06)$ & - & - & - & - & - & - & - \\
\hline
\end{tabular}

Table 3 shows that different materials have different optimum thermal contrasts i.e. the lowest size estimation percentage error for detection. The table shows that white mosaic tile has the smallest average absolute percentage error i.e. $1.01 \%$ with thermal contrast of $6^{\circ} \mathrm{C}$. Grey tile has largest average absolute percentage error i.e. $32.69 \%$ with SD equals 
to $13.82 \%$ at thermal contrast equals to $2^{\circ} \mathrm{C}$. Different materials can achieve different thermal contrasts within the period of data collection, e.g. fair-face concrete can obtain thermal contrast as high as $10^{\circ} \mathrm{C}$ whereas reflective white tile can only obtain maximum thermal contrast up to $4^{\circ} \mathrm{C}$. It is because of the difference in their emissivity; for fair-face concrete has higher emissivity than reflective white tile. It is also observed that the average absolute percentage error decreases when thermal contrast increases at most of the materials. Besides, SD values are usually high when thermal contrast is within $1^{\circ} \mathrm{C}-2^{\circ} \mathrm{C}$. They are ranging from $3.45 \%$ at blue mosaic to $21.27 \%$ at mixed mosaic. The trend of the average absolute percentage error of estimated size to absolute thermal contrast of all 8 types of finishes materials are shown in Fig 12.

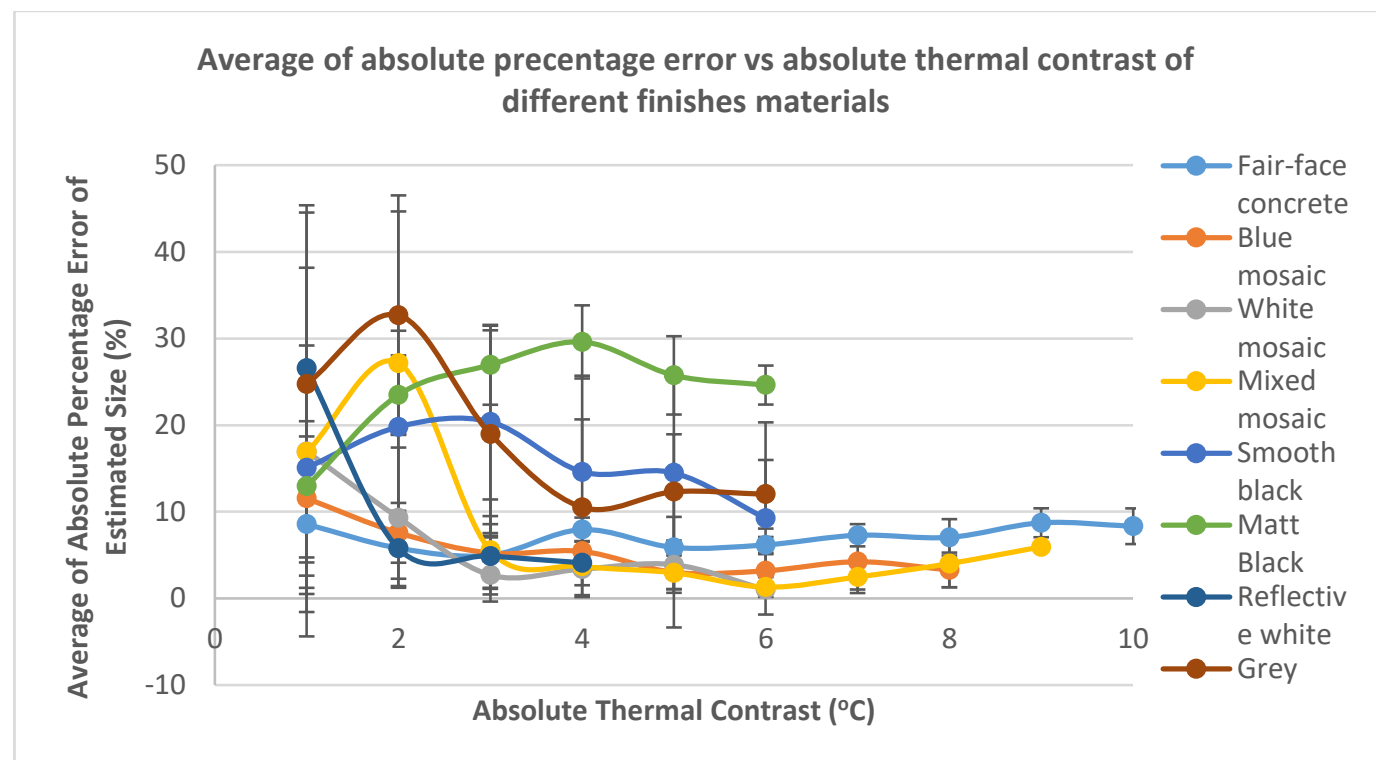

Fig 12: Average absolute percentage error vs absolute thermal contrast of different finishes materials ranging from $1^{\circ} \mathrm{C}$ to $10^{\circ} \mathrm{C}$

As shown in the figure, fair-face concrete and blue mosaic have relative constant absolute percentage error which is within $10 \%$ error throughout the range of thermal contrasts. Grey tile has the highest average absolute percentage error i.e. $32.69 \%$ and decreases dramatically to $18.99 \%$ when it reaches $3^{\circ} \mathrm{C}$ thermal contrast. Same phenomenon is observed when mixed mosaic tile reaches $3{ }^{\circ} \mathrm{C}$ thermal contrast, the absolute percentage error decreases sharply from $27.16 \%$ to $5.53 \%$. The absolute percentage error on smooth black tile start to decrease when it researches $4^{\circ} \mathrm{C}$ thermal contrast. Therefore, it shows that most of the materials started to have a significant decrease in the absolute percentage error when over $3-4^{\circ} \mathrm{C}$ thermal contrast except matt black tile. When referring to Fig 11 , the absolute percentage error of matt black tile started to increase after $2{ }^{\circ} \mathrm{C}$ and it becomes stable at absolute percentage error around $30 \%$. The reason for this may because the high emissivity of matt black tiles which absorb a large amount of heat energy during heat absorption period and the boundary of the tiles also affected the thermal signals of the defect. For comparison of standard deviation (SD), the SD of the absolute percentage error decreases when thermal contrast increases in most of the materials. The continuous decreasing trend of standard deviation can be observed on most of the finishes materials except on smooth black tiles. Smooth black tile has relatively constant standard deviation along with the change of thermal contrast (around $13.43 \%)$.

\section{Conclusion}

In conclusion, this study collect data throughout the three periods: heat absorption, transition period and heat dissipation period to determine the optimum thermal contrast for optimum detectability for different finishes materials. For example, with the same absolute thermal contrast of $2^{\circ} \mathrm{C}$, the absolute percentage error of size estimation obtained on fairface surface is $5.8 \%$ while it is $36.69 \%$ on surface with grey tile. In other words, absolute thermal contrast of $2^{\circ} \mathrm{C}$ is sufficient for revealing a debond underneath fair-face concrete to be observed with $5.8 \%$ error. This study gives out a quantitative reference on how "visible" can a debond be shown by IRT in terms of the accuracy of the observed anomaly signals of debond in reflecting their actual size. There are several observations in this study:

1. Subsurface defects will change from hot spots during heat absorption to cold spot during heat dissipation through a transition period. Defects seemed to be disappeared (with the fixed temperature range) at transition period because thermal contrast between defects and the surrounding intact areas tends to zero.

2. It shows that each finishes material has their own inversely proportional relationship between thermal 
contrast and percentage error of the estimated size, i.e. the absolute percentage error decreases when absolute thermal contrast increases.

3. Different materials can achieve different thermal contrasts within the period of data collection, e.g. fairface concrete can obtain thermal contrast as high as $10^{\circ} \mathrm{C}$ whereas reflective white tile can only obtain maximum thermal contrast up to $4^{\circ} \mathrm{C}$. This is because of their difference in emissivity.

4. The results show that most of the materials started to have a significant decrease in the absolute percentage error when over $3-4^{\circ} \mathrm{C}$ thermal contrast except matt black tile.

5. It is also observed that the SD of the absolute percentage error decreases when thermal contrast increases in most of the materials except smooth black tile which has a relatively constant SD, i.e. $13.43 \%$.

6. It shows that fair-face concrete and blue mosaic have relative constant absolute percentage error which is within $10 \%$ error throughout the whole range of thermal contrasts.

This study only includes one day of 13-hr data collection and the experiment was carried out in winter time with relatively low temperature (ambient temperature ranging from $7.9^{\circ} \mathrm{C}-14.2^{\circ} \mathrm{C}$ ). Therefore, it is recommended to have data collections throughout the year with different seasons and temperature ranges for more promising results.

\section{REFERENCES}

1. Washer, G., et al., Guidelines for Thermographic Inspection of Concrete Bridge Components in Shaded Conditions. Transportation Research Record, 2013(2360): p. 13-20.

2. Clark, M.R., D.M. McCann, and M.C. Forde, Application of infrared thermography to the non-destructive testing of concrete and masonry bridges. NDT \& E International, 2003. 36(4): p. 265-275.

3. Hiasa, S., R. Birgul, and F.N. Catbas, Effect of Defect Size on Subsurface Defect Detectability and Defect Depth Estimation for Concrete Structures by Infrared Thermography. Journal of Nondestructive Evaluation, 2017. 36(3).

4. Lai W.L, P.C.S. Boundary and size estimation of debonds in external wall finishes of high-rise buildings using Infrared thermography. in 11th Quantitative Infrared Thermography (QIRT 2012). 2012. QIRT.

5. Holst, G.C., Common sense approach to thermal imaging. 2000, Winter Park, Fla. : Bellingham, Wash.: JCD Publishing

SPIE Optical Engineering Press.

6. Hiasa, S., Investigation of infrared thermography for subsurface damage detection of concrete structures, in Department of Civil, Environmental, and Construction Engineering. 2016, University of Central Florida: Florida.

7. Hiasa, S.H., R. Birgul, and N. Catbas, A data processing methodology for infrared thermography images of concrete bridges. Computers \& Structures, 2017. 190: p. 205-218.

8. Khan, F., et al., Modeling and experimental implementation of infrared thermography on concrete masonry structures. Infrared Physics \& Technology, 2015. 69: p. 228-237.

9. McCann, D. and M. Forde, Review of NDT methods in the assessment of concrete and masonry structures. NDT \& E International, 2001. 34(2): p. 71-84.

10. Maldague, X., Theory and practice of infrared technology for nondestructive testing. 2001, New York: Wiley.

11. Clark, M., M. Gordon, and M.C. Forde, Issues over high-speed non-invasive monitoring of railway trackbed. NDT \& E International, 2004. 37(2): p. 131-139. 